\title{
MAGNETIC RESONANCE IMAGING OF MENISCAL AND CRUCIATE INJURIES OF THE KNEE
}

\author{
N. R. BOEREE, A. F. WATKINSON, C. E. ACKROYD, C. JOHNSON
}

From Southmead General Hospital and the Bristol MRI Centre, Bristol

\begin{abstract}
We investigated 133 knees with suspected meniscal or cruciate injuries by magnetic resonance imaging, and compared the findings with those at arthroscopy. MRI was found to be highly sensitive, specific and accurate in the evaluation of the menisci and the anterior cruciate ligament.
\end{abstract}

Clinical assessment of damage to the menisci and the cruciate ligaments is known to be inaccurate (Jackson and Abe 1972; Ireland, Trickey and Stoker 1980; Simonsen et al 1984). Reliable imaging could avoid the need for arthroscopy in many patients. Contrast arthrography can provide useful information but the method has its disadvantages. Magnetic resonance imaging (MRI) offers a non-invasive and safe alternative, and this study aims to assess its reliability.

\section{MATERIALS AND METHODS}

Of 203 patients who had undergone MRI of the knee between June 1987 and July 1989 we selected for study 133 in whom arthroscopy had also been undertaken. All knees had been investigated for possible meniscal or cruciate injury.

A Picker 0.5 Tesla MRI body scanner was used, with a surface coil placed around the slightly flexed and internally rotated knee. The early investigations comprised 12 coronal and 16 parasagittal, T1-weighted, contiguous sections of $5 \mathrm{~mm}$ thickness. Proton density images allow quicker scan times, and this has now become the usual method of investigation. The scans were examined without reference to the patient's history or to the original radiologist's report.

N. R. Boeree, BSc, FRCS, FRCS Ed, Orthopaedic Registrar

A. F. Watkinson, MSc(Oxon), FRCS, Registrar in Radiology

Bristol Royal Infirmary, Marlborough Street, Bristol BS2 8HW,

England.

C. E. Ackroyd, FRCS, Consultant Orthopaedic Surgeon

C. Johnson, FRCR, Consultant Radiologist

Southmead Hospital, Westbury-on-Trym, Bristol BS10 5NB, England.

Correspondence should be sent to Mr N. R. Boeree.

(C) 1991 British Editorial Society of Bone and Joint Surgery

0301-620X/91/3115\$2.00

J Bone Joint Surg [Br] 1991 ; 73-B:452-7.

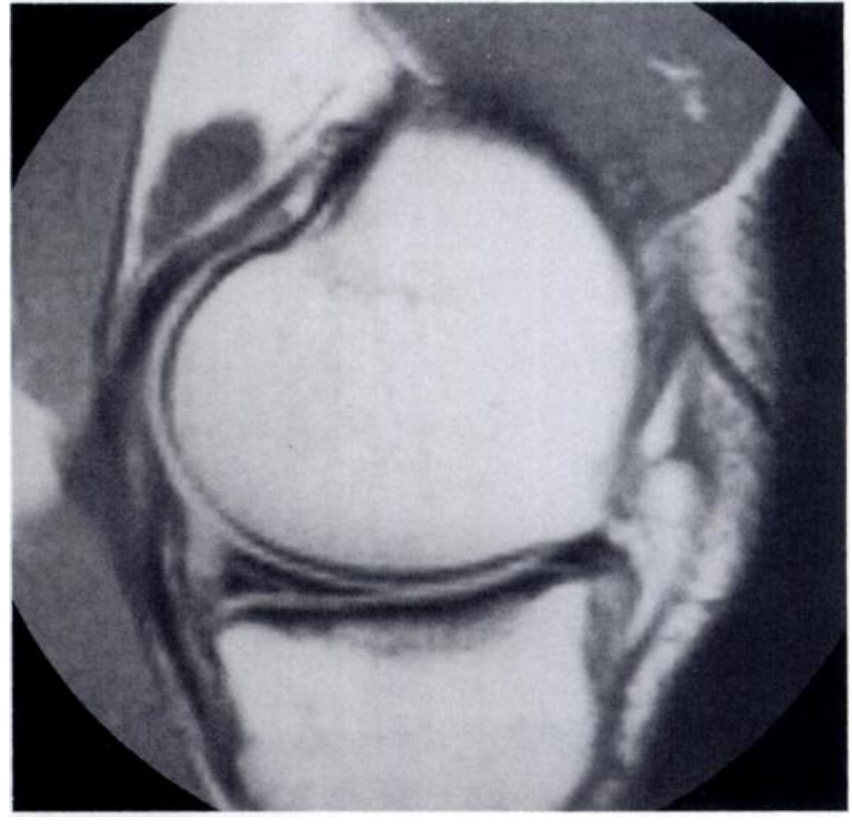

Fig. 1

MRI demonstrating a tear of the posterior horn of the medial meniscus, represented by an area of high signal extending to the inferior articular surface.

An area of high signal within the substance of a meniscus was regarded as a tear if it extended to one or both articular surfaces (Fig. 1). If the articular surfaces were not reached, the high signal was interpreted as an area of mucoid degeneration (Fig. 2) (Stoller et al 1987). A cruciate ligament was presumed to be ruptured or absent if it was not visualised (Fig. 3) or appeared as a diffuse, amorphous structure of high signal (Fig. 4) (Turner et al 1985). The normal anterior cruciate ligament (ACL), has a banded appearance, and the posterior cruciate appears thicker and has a lower signal (Fig. 5). 


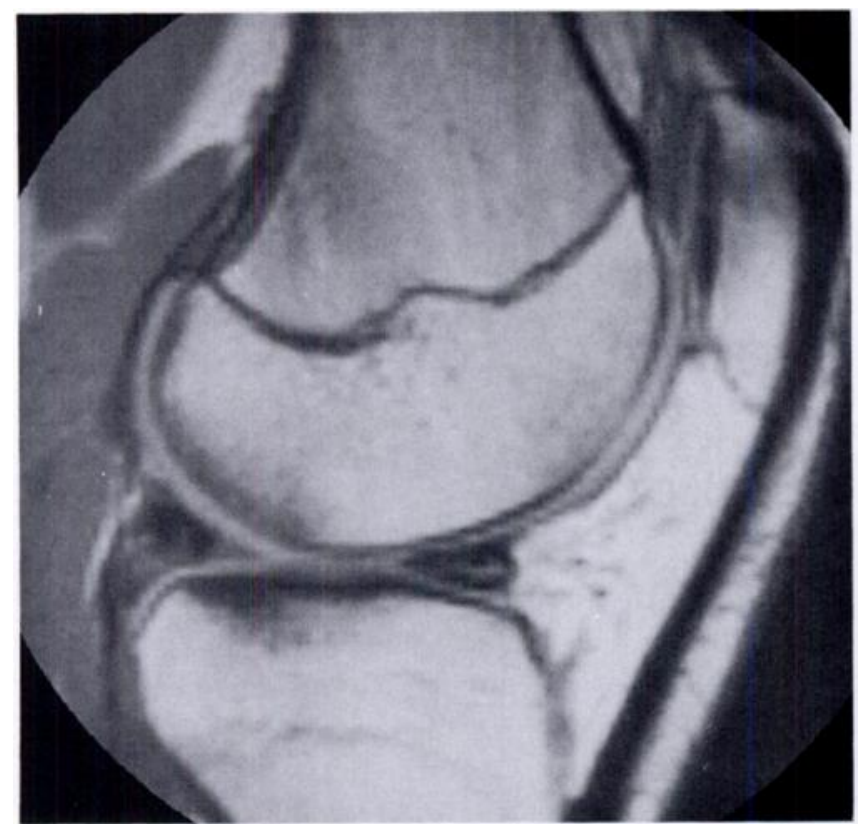

Fig. 2

Internal mucoid degeneration of the anterior horn of the lateral meniscus.

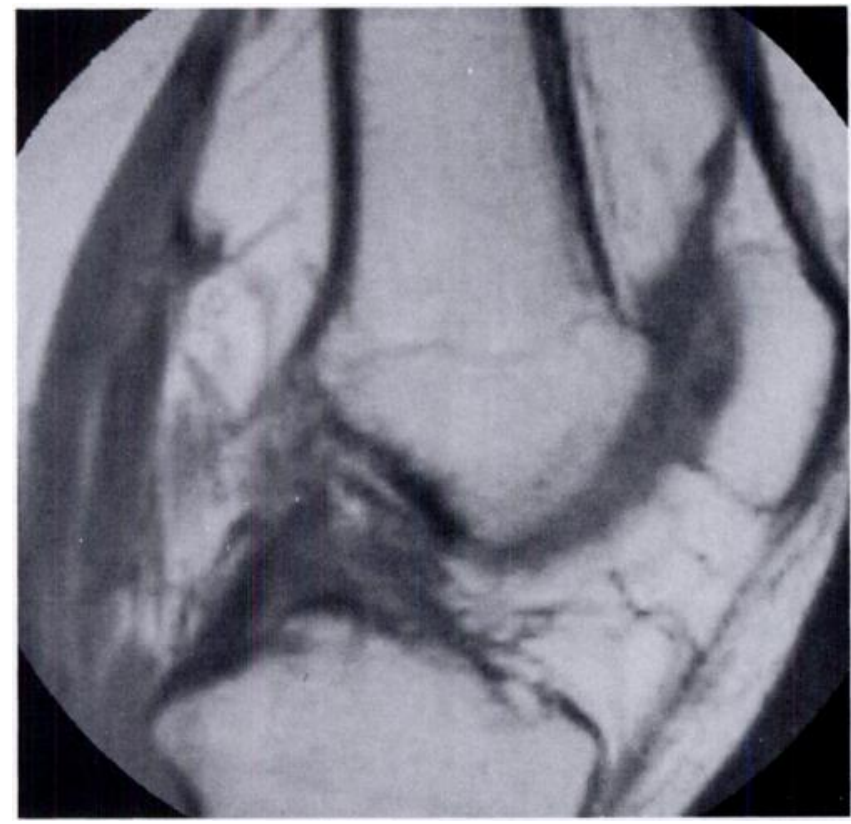

Fig. 4

Rupture of the anterior cruciate ligament, which appears as an area of diffuse, amorphous high signal.

The clinical records of each patient were independently reviewed. Their average age was 34 years (range 7 to 71 ); 108 were male and 25 were female. There were 69 left and 64 right knees. In $31 \%$ there was no history of trauma, and in a further $13 \%$, although the knee had been injured, the nature of the injury could not be

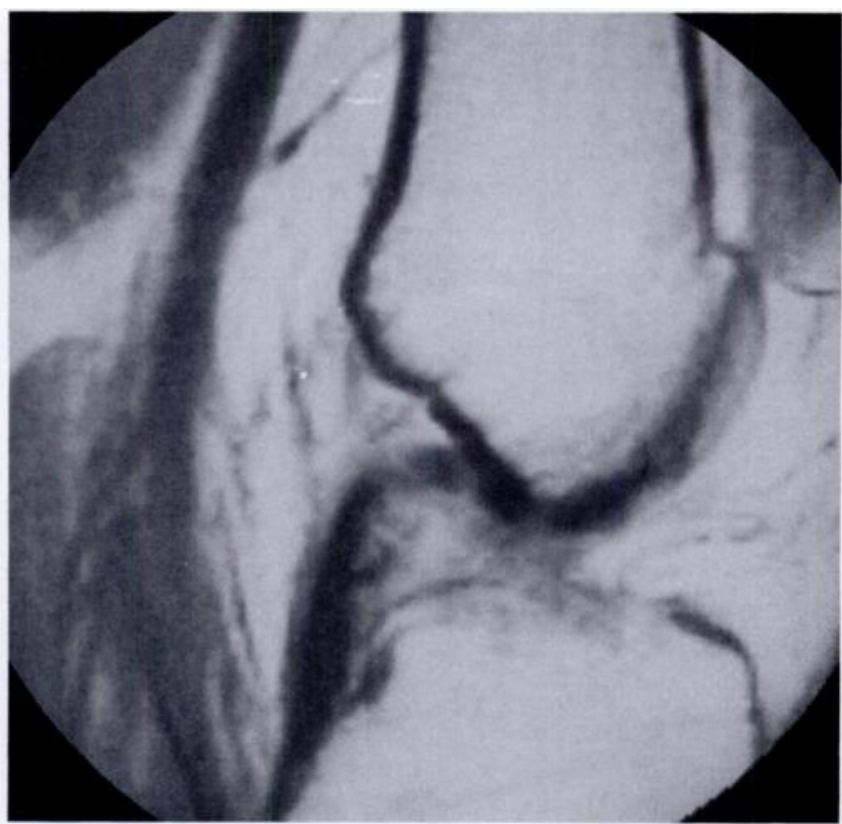

Fig. 3

Absence of the anterior cruciate ligament.

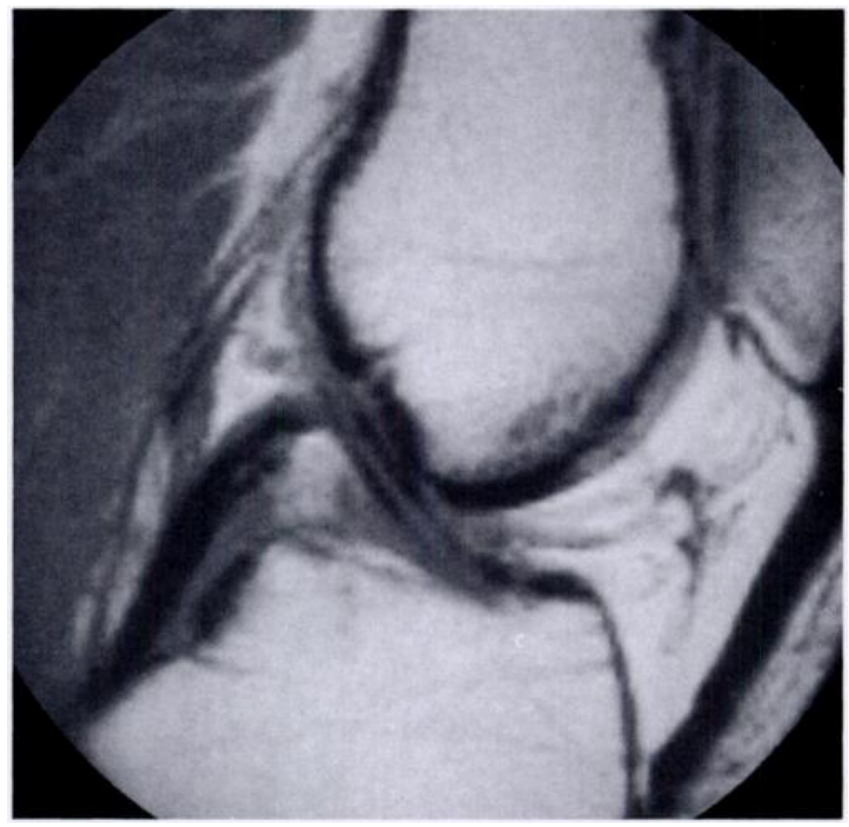

Fig. 5

The normal appearances of the posterior and anterior cruciate ligaments.

recalled. A well described traumatic event was recorded in the remaining $56 \%$, the commonest being a twisting injury ( $43 \%)$.

To evaluate the sensitivity, specificity and accuracy of MRI, the findings at arthroscopy were taken to be the true diagnosis. Sensitivity was calculated from the 
number of true positive results divided by the sum of the true positive results and the false negative results. Specificity was calculated from the number of true negative results divided by the sum of the true negative results and the false positive results. Accuracy was calculated from the sum of the true positive and the true negative results divided by the total number of patients who underwent arthroscopy.

\section{RESULTS}

The indication for arthroscopy was the MRI finding of a torn meniscus in 97 of the 133 cases $(72.9 \%)$. Five patients (3.8\%) underwent arthroscopy prior to repair of a ruptured ligament diagnosed by MRI. Seven patients (5.3\%) had MRI scans because of symptoms which persisted after negative arthroscopy. In 24 cases $(18 \%)$ arthroscopy was performed on clinical grounds despite the normal appearance of the menisci and cruciates on the MRI.
Table I. The correlation between MRI and arthroscopic diagnoses for lesions of the medial meniscus

\begin{tabular}{lrrrrrl}
\hline & \multicolumn{4}{l}{$\begin{array}{l}\text { Arthroscopic diagnosis } \\
\text { (number and per cent) }\end{array}$} \\
\cline { 2 - 8 } MRI diagnosis & Normal & \multicolumn{1}{l}{ Torm } & Absent \\
\hline Normal & 63 & 47.4 & 2 & 1.5 & 0 & \\
Torn & 6 & 4.5 & 58 & 43.6 & 0 & \\
Absent & 0 & & 3 & 2.25 & 1 & 0.75 \\
\hline
\end{tabular}

Table III. The correlation between MRI and arthroscopic diagnoses for lesions of the ACL

\begin{tabular}{lrrrrrr}
\hline & \multicolumn{4}{l}{$\begin{array}{l}\text { Arthroscopic diagnosis } \\
\text { (number and per cent) }\end{array}$} \\
\cline { 2 - 7 } MRI diagnoses & Normal & \multicolumn{2}{l}{ Lax } & \multicolumn{1}{l}{ Not seen } \\
\hline Normal & 89 & 66.9 & 0 & & 1 & 0.75 \\
High signal & 4 & 3.0 & 2 & 1.5 & 8 & 6.0 \\
Not seen & 0 & & 5 & 3.75 & 24 & 18.0 \\
\hline
\end{tabular}

The correlations between MRI and arthroscopic diagnoses are given in Tables I to IV. Table V shows the sensitivity, specificity and accuracy of MRI. The menisci recorded as normal included those that demonstrated internal mucoid degeneration on MRI scanning, or fraying on arthroscopic inspection.

In certain cases disagreement was noted between the MRI and arthroscopic findings.

Menisci

False negative MRI. In three patients the menisci were considered normal on MRI but a tear was seen at subsequent arthroscopy. Of these, two were displaced bucket-handle tears of the medial meniscus found in patients who were undergoing arthroscopy for diagnosed tears of the lateral meniscus. The third patient was noted to have a cyst of the lateral meniscus on MRI, but the oblique tear of the under surface of the meniscus, seen at arthroscopy, was not demonstrated by MRI. Small, or deficient, but not evidently torn menisci, were diagnosed on five scans; at arthroscopy all were found to be torn.

False positive MRI. In eight cases, tears diagnosed on MRI were not confirmed at arthroscopy. In all but one of these the tear was considered to be present in the posterior horn of one or other meniscus.

In the seven knees scanned because of persisting symptoms after reportedly normal arthroscopies, posterior horn tears were diagnosed in four patients and confirmed at subsequent arthroscopy in three of them.

Other abnormalities. Cysts were diagnosed by MRI in 12 menisci (Fig. 6), six lateral and six medial. Nine of these

Table II. The correlation between MRI and arthroscopic diagnoses for lesions of the lateral meniscus

\begin{tabular}{llllllll}
\hline & & \multicolumn{4}{l}{$\begin{array}{l}\text { Arthroscopic diagnosis } \\
\text { (number and per cent) }\end{array}$} \\
\cline { 2 - 7 } MRI diagnosis & Normal & Torn & & Absent \\
\hline Normal & 99 & 74.4 & 1 & 0.75 & 0 & \\
Torn & 2 & 1.5 & 25 & 18.8 & 0 & \\
Absent & 0 & & 2 & 1.5 & 4 & 3.0 \\
\hline
\end{tabular}

Table IV. The correlation between MRI and arthroscopic diagnoses for lesions of the posterior cruciate ligament

\begin{tabular}{lllllll}
\hline & \multicolumn{3}{l}{$\begin{array}{l}\text { Arthroscopic diagnosis } \\
\text { (number and per cent) }\end{array}$} \\
\cline { 2 - 7 } MRI diagnosis & Normal & Lax & \multicolumn{3}{l}{ Not seen } \\
\hline Normal & 55 & 41.4 & 0 & & 73 & 54.9 \\
High signal & 0 & 1 & 0.75 & 3 & 2.25 \\
Not seen & 0 & 0 & 1 & 0.75 \\
\hline
\end{tabular}

were noted on clinical examination, and the remaining three were confirmed at surgery.

Discoid deformity of the lateral meniscus (Fig. 7) was demonstrated on MRI in four knees, in one of whom the condition had not been suspected clinically. In two cases the MRI diagnosis of disruption was confirmed arthroscopically.

ACL rupture

False positive MRI. There were 11 knees in which the ACL gave an increased signal or was not visualised on 
Table V. The sensitivity, specificity and accuracy of MRI judged against the arthroscopic diagnosis

\begin{tabular}{|c|c|c|c|c|c|c|}
\hline & \multicolumn{2}{|c|}{ Sensitivity } & \multicolumn{2}{|c|}{ Specificity } & \multicolumn{2}{|l|}{ Accuracy } \\
\hline & $\mathbf{N} / \mathbf{N}$ & Per cent & $\mathbf{N} / \mathbf{N}$ & Per cent & $\mathbf{N} / \mathbf{N}$ & Per cent \\
\hline Medial meniscus & $58 / 60$ & 96.7 & $63 / 69$ & 91.3 & $121 / 129$ & 93.8 \\
\hline Lateral meniscus & $25 / 26$ & 96.1 & $99 / 101$ & 98.0 & $124 / 127$ & 97.6 \\
\hline ACL & $32 / 33$ & 97.0 & $89 / 100$ & 89.0 & $121 / 133$ & 91.0 \\
\hline
\end{tabular}

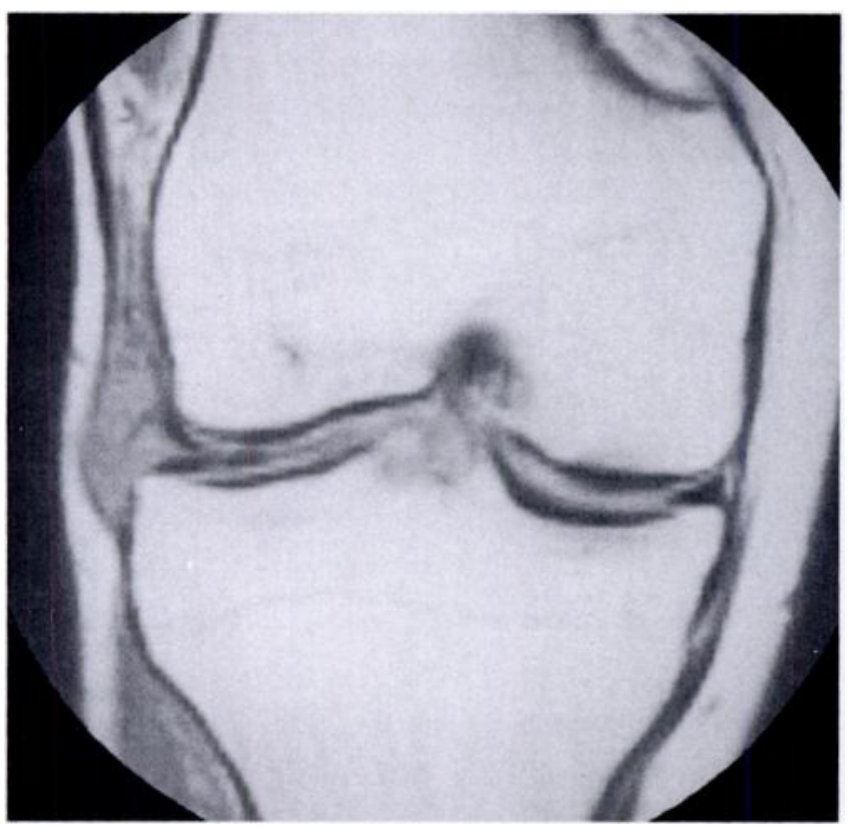

Fig. 6

A cyst of the lateral meniscus.

MRI but in which arthroscopy revealed the ligament to be intact.

\section{ACL rupture}

False negative MRI. One patient, who proved to have had a recent rupture of the $A C L$, was considered to have a normal ligament on MRI.

Arthroscopy after negative MRI. None of the 24 patients who underwent arthroscopy despite normal MRI appearances were found to have significant meniscal pathology. Degenerative changes were observed in nine; four of them derived some initial benefit from arthroscopic washout. A plical fold was noted in four, but in only one of these was it thought to be significant.

Complications. Arthroscopy was associated with a complication rate of $2.3 \%$. One knee became infected, and two patients required readmission to hospital for treatment of haemarthroses. Aspiration of joint effusion was required in 15 patients $(11.3 \%)$ prior to their discharge.

Accuracy of clinical diagnosis. A clinical diagnosis of meniscal or cruciate derangement had been made clinically in $77 \%$ of cases. In the remainder the clinical
Table VI. The sensitivity, specificity and accuracy of clinical diagnosis judged against the arthroscopic diagnosis

\begin{tabular}{llll}
\hline & $\begin{array}{l}\text { Sensitivity } \\
\text { (per cent) }\end{array}$ & $\begin{array}{l}\text { Specificity } \\
(\text { per cent) }\end{array}$ & $\begin{array}{l}\text { Accuracy } \\
(\text { per cent) }\end{array}$ \\
\hline Medial meniscus & 67.7 & 67.2 & 67.5 \\
Lateral meniscus & 48.3 & 88.7 & 79.4 \\
ACL & 55.9 & 93.5 & 83.3 \\
\hline
\end{tabular}

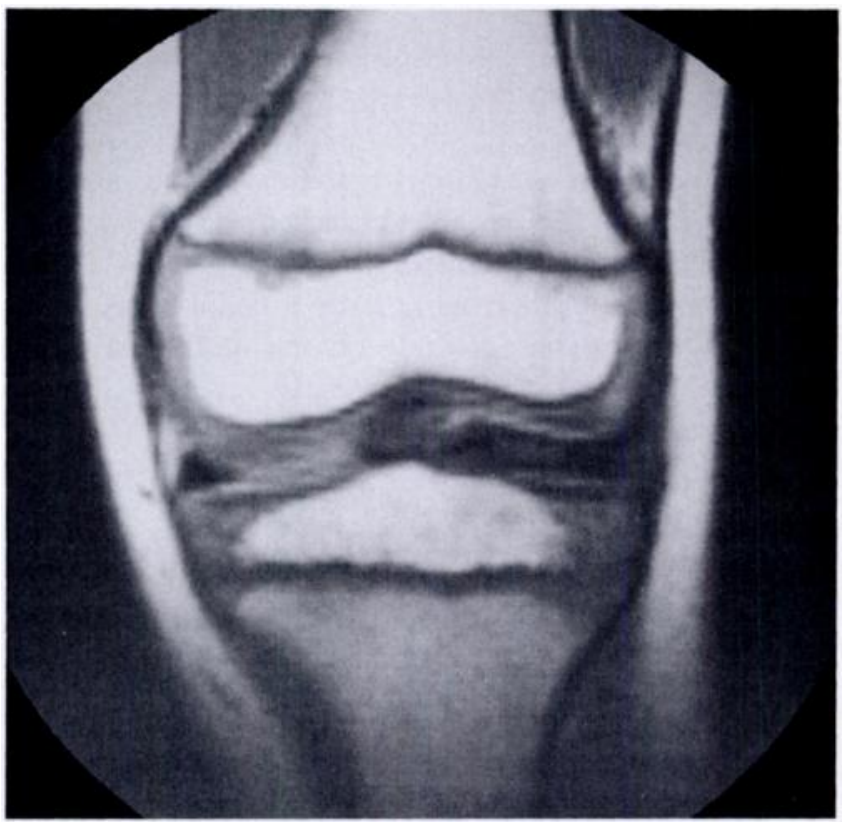

Fig. 7

A discoid lateral meniscus in a 9-year-old boy.

diagnosis was not specified, and MRI scan was undertaken to exclude pathology. The sensitivity, specificity and accuracy of clinical diagnosis is shown in Table VI.

Patients who did not undergo arthroscopy. There were a further 70 patients, with clinically suspected meniscal or cruciate ligament abnormalities, who were excluded from the above study because arthroscopy had not been undertaken. In 60 of these, this was because the MRI was negative. If these MRI findings were correct, then there were many more false positive clinical diagnoses than Table VI suggests.

\section{DISCUSSION}

This study has confirmed the unreliability of clinical diagnosis of meniscal and cruciate ligament lesions. Arthroscopy provides an accurate diagnosis in from $84 \%$ to $98.6 \%$ of cases (Jackson and Abe 1972; Dandy and Jackson 1975; Ireland et al 1980), and allows treatment of meniscal tears. However, in many patients nooperative treatment is found necessary. As a diagnostic method, 
arthroscopy exposes the patient to the discomforts and risks associated with anaesthesia and an operation. Sherman et al (1986) reported a complication rate of $8.3 \%, 4.8 \%$ being major. A significant complication rate was also demonstrated in our series of arthroscopies.

Arthrography is a less intrusive technique, but it is nevertheless invasive and may be painful. Complications have been reported (Ansell 1976), and the procedure requires approximately 24 radiographic exposures. Accurate diagnostic information is obtained in $77 \%$ to $95 \%$ of cases but interpretation can be difficult (Gillies and Seligson 1979; Ireland et al 1980; Thijn 1982; Pavlov et al 1983; Shakespeare and Rigby 1983; Dumas and Eddé 1986).

Magnetic resonance imaging is non-invasive and causes no discomfort. It appears to be without risks, and does not expose the patient to radiation. Some patients $(1 \%$ to $2 \%$ ) experience claustrophobia.

No single method of investigation of the knee is totally reliable. The accuracy of one method must be related to the findings of an alternative, and differences may represent failure of either technique.

There were eight patients in whom a meniscal tear, demonstrated by MRI, was not subsequently confirmed at arthroscopy. This discrepancy may represent over interpretation of the MRI appearances of internal mucoid degeneration, misinterpretation of normal anatomy (Watanabe et al 1989), or inadequate arthroscopic technique. Most tears were diagnosed in the posterior horn of the meniscus where they may be missed by the arthroscopist in 5\% of cases (Ireland et al 1980). It is noteworthy that three of the four tears diagnosed by MRI after an apparently normal arthroscopy were later confirmed at repeat arthroscopy. Such tears were presumably missed at the first procedure.

The MRI appearance of a small or deficient meniscus, in a patient who has not had a previous meniscectomy, was, in every instance, associated with a tear. This finding should therefore be regarded as positive evidence of a meniscal tear and it does not represent a failing of MRI. Meniscal cysts were well demonstrated on MRI, which proved more sensitive than clinical examination.

In four patients the ACL was found to be normal despite giving an increased signal on MRI. In another seven cases with similar MRI findings the ligament appeared intact but lax at arthroscopy. Poor visualisation of a normal ACL may be due to partial voluming, which is a problem inherent in imaging techniques which use contiguous slices. However, the fact that several of these ligaments appeared to be lax may suggest the presence of interstitial rupture or stretching. Absence or rupture of the anterior cruciate ligament may be supported by an altered appearance of a posterior cruciate which appears more curled up than usual (Fig. 8).

The posterior cruciate ligament can be clearly demonstrated on MRI, but the reliability of its assessment is difficult to corroborate since the ligament is often not seen at arthroscopy. Good correlation with the clinical sign of posterior cruciate laxity was observed in the few cases in which MRI suggested rupture.

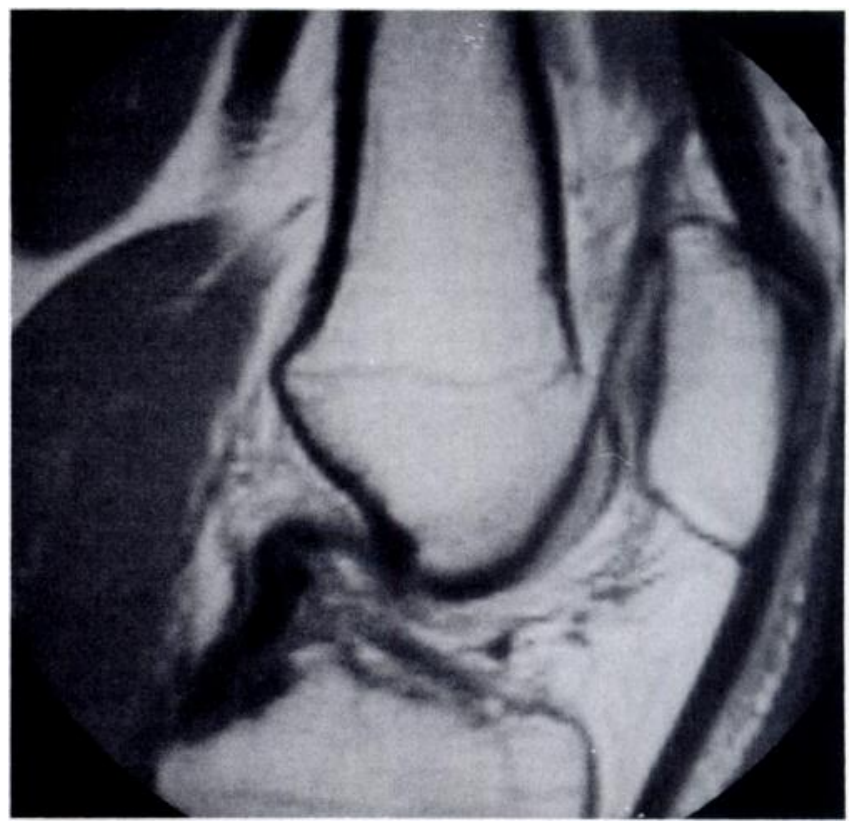

Fig. 8

A posterior cruciate ligament appearing more curled up than usual (compare with Figure 5), supporting the diagnosis of rupture of the anterior cruciate ligament where this structure is poorly visualised.

Conclusion. In this study, close agreement between MRI and arthroscopic diagnoses has been demonstrated, confirming the results of a previous report by Polly et al (1988). MRI would appear to be at least as effective as arthrography in the evaluation of the menisci and cruciate ligaments of the knee. The accuracy of MRI should allow more appropriate targeting of arthroscopy to those patients likely to obtain therapeutic benefit, perhaps eliminating the need for arthroscopy in one-third to onehalf of those considered, on clinical grounds, to have meniscal or cruciate derangement. Such a reduction in the number of invasive procedures should allow a corresponding reduction in the financial and manpower resources required for the treatment of knee injuries.

The authors wish to extend their thanks to the staff of the Frenchay MRI Centre, and in particular to Dr I. Watt, Consultant Radiologist, and Miss J. Waring, Senior Radiographer, for their assistance.

No benefits in any form have been received or will be received from a commercial party related directly or indirectly to the subject of this article.

\section{REFERENCES}

Ansell G. Arthrography. In: Ansell G, ed. Complications in diagnostic radiology. Oxford, etc: Blackwell Scientific Publications, 1976: 372-3. 
Dandy DJ, Jackson RW. The diagnosis of problems after meniscectomy. J Bone Joint Surg [ Br] 1975; 57-B:349-52.

Dumas JM, Eddé DJ. Meniscal abnormalities: prospective correlation of double-contrast arthrography and arthroscopy. Radiology 1986 $160: 453-6$.

Gillies H, Seligson D. Precision in the diagnosis of meniscal lesions: a comparison of clinical evaluation, arthrography, and arthroscopy J Bone Joint Surg [ Am] 1979; 61-A:343-6.

Ireland J, Trickey EL, Stoker DJ. Arthroscopy and arthrography of the knee: a critical review. J Bone Joint Surg [Br] 1980; 62-B:3-6.

Jackson RW, Abe I. The role of arthroscopy in the management of disorders of the knee : an analysis of 200 consecutive examinations. J Bone Joint Surg [Br] 1972; 54-B:310-22.

Pavlov H, Warren RF, Sherman MF, Cayea PD. The accuracy of double-contrast arthrographic evaluation of the anterior cruciate ligament. J Bone Joint Surg [Am] 1983; 65-A :175-83.

Polly DW, Callaghan JJ, Sikes RA, McCabe JM, McMahon K, Savory CG. The accuracy of selective magnetic resonance imaging compared with the findings of arthroscopy of the knee. $J$ Bone Joint Surg [Am] 1988; 70-A:192-8.
Shakespeare DT, Rigby HS. The bucket-handle tear of the meniscus: a clinical and arthrographic study. J Bone Joint Surg [Br] 1983; 65B:383-7.

Sherman OH, Fox JM, Sayder SJ, et al. Arthroscopy - "no problem surgery": an analysis of complications in two thousand six hundred and forty cases. J Bone Joint Surg [Am] 1986; 68-A :256-65.

Simonsen $\mathbf{O}$, Jensen J, Mouritsen P, Lauritzen J. The accuracy of clinical examination of injury of the knee joint. Injury 1984; 16 : 96-101.

Stoller DW, Martin C, Crues JV, Kaplan L, Mink JH. Meniscal tears: pathologic correlation with MR imaging. Radiology 1987; 163; 731-5.

Thijn CJ. Accuracy of double-contrast arthrography and arthroscopy of the knee joint. Skeletal Radiol 1982; 8:187-92.

Tumer DA, Prodromos CC, Petasnick JP, Clark JW. Acute injury of the ligaments of the knee: magnetic resonance evaluation. Radiology 1985; 154:717-22.

Watanabe AT, Carter BC, Teitelbaum GP, Bradley WG. Common pitfalls in magnetic resonance imaging of the knee. $J$ Bone Joint Surg [ Am] 1989; 71-A :857-62. 